\title{
Occupational Stress And Job Satisfaction In White- And Blue-Collar Workers
}

Rudy Nydegger (E-mail: Nydegger@ union.edu), Union College

\begin{abstract}
The relationship between job satisfaction and stress has been examined in numerous settings. In the present study, a two-part occupational stress survey was given tol40 subjects in white-and blue-collar occupations. Twelve possible stressor variables divided into three levels of stress: independent; group; and organizational were analyzed. A factorial ANOVA analysis was conducted, and revealed that there was a significant main effect result for types of stress experienced by the workers in the two types of organizations, but there were no differences between the organizations in terms of amount or types of stress, nor were there any differences between male and female employees. The relationship between stress and job satisfaction was discussed, and suggestions were made as to ways organizations can improve job satisfaction by paying attention to some of the sources of stress.
\end{abstract}

\section{Introduction}

(2)

tress is "an adaptive response, mediated by individual characteristics and/or psychological processes, that is a consequence of any external action, situation, or event that places special physical and/or psychological demands upon a person" (Ivancevich \& Matteson, 1980). The external actions, which are beyond a person's control, that cause physiological, cognitive, and behavioral strain on a person are known as stressors. Occupational stressors cause major problems for both individual organizations and employees themselves. Research by Matteson \& Ivancevich (1987) estimated that because of stress-related illness the financial losses to organizations were approximately $\$ 60$ billion, and that number is likely far higher today. One nationwide survey by Northwestern National Life Insurance Company (1991) demonstrated that 46\% of American workers felt that their jobs were very or somewhat stressful. Further, $27 \%$ of the respondents claimed that their jobs were the single greatest source of stress in their lives, and $72 \%$ experienced frequent physical and mental stress-related problems. One need only to browse through popular, professional, and scholarly publications to find that stress is an increasingly important and relevant topic to people in general, organizations, businesses, researchers, and health care providers and professionals.

When stress occurs to individuals, there is not a clear and consistent response to that stress, and there are considerable individual differences in terms of what is stressful, and how that stress is expressed (Greenberg \& B aron, 1995). To some degree, the potential stressors that people face depend upon their cognitive appraisal of the stress (Lazarus \& Folkman, 1984). Lazarus' Transactional Process Theory states that stress occurs when a person perceives a particular situation as threatening, or has the feeling that the situation is beyond his or her control, and that he or she is incapable of coping with the potential danger of the situation. Thus, stress is derived from and the response molded by cognitive processes. A person will develop stress reactions when situations arise that he or she evaluates as stressful (Greenberg \& Baron, 1995).

With this fact in mind, it must also be remembered that some occupations are inherently more stressful than others, or at least this is the perception. Traditionally, jobs like air traffic controller, police, fire fighters, physicians, dentists, and high-level executives are considered to be stressful, and in fact there are studies that would tend to con-

Readers with comments or questions are encouraged to contact the author via email. 
firm this. Mohler (1983) found that air traffic controllers do tend to experience high levels of stress on the job. Medical doctors likewise feel that work stress is a problem for them (Krakowski, 1982; Roeske, 1981), and dentistry too, is considered to be high stress (Cooper, Mallinger, \& Kahn, 1978; DiMatteo, Shugars, \& Hays, 1993). However, it is also true that there are considerable individual differences between people in these occupations in terms of how stressful their jobs seem to be, and some other studies have found results that are somewhat surprising. For example, one study found that among physicians, pharmacists, and nurses, the nurses reported the highest levels of work stress (Wolfgang, 1988). Other interesting studies examined the assumption that police and firefighters experience stress on the job because of the physical danger they face. Rather that being the main source of stress, it was discovered that the excitement and challenge of dealing with potentially dangerous situations was motivating and "enriching" to many police and fire fighters (Jermier, Gamines, \& McIntosh, 1989; Riggio \& Cole, 1995). In fact, studies of police officers suggest that they suffer from the same sources of stress, such as increased responsibilities and workloads, and difficulties with co-workers as do other occupations (Brown, Cooper, \& Kircaldy, 1996). This would indicate, that although it seems logical to assume that some jobs are more stressful than others, it is not clear as to what the actual sources may be for each individual worker, and how that stress is manifested.

It does seem clear that jobs become increasingly stressful to the extent that they require: making decisions; constant monitoring of devices or materials; repeated exchange of information with others; unpleasant physical conditions; and performaing unstructured rather than structured tasks (Greenberg \& Baron, 1997). This is consistent with research by Marino and White (1985), which found that the severity of organization stressors might be different, based on the level or type of job.

The typical sources of work stress may be found in the situation or in the individual workers. Certainly, some workers seem to be more susceptible to stress than others. For example, Type A behavior patterns typified by aggressively pursuing goals, time urgency, underlying hostility, and competitiveness have been related to stressrelated difficulties (Friedman \& Rosenman, 1974; Rosenman, 1978). Type A behavior patterns have even been linked to increased levels of cardio-vascular disease (Booth-Kewley \& Friedman, 1987; Schauerbroeck, Ganster, \& Kemmerer, 1994). It has also been argued that people that have the personality trait of "hardiness" are more resistant to the negative effects of stress (Kobasa, 1982).

Organizational sources of stress include a variety of different things. For example, work overload is a frequently cited source of stress as measured by such things as elevated serum cholesterol and increased heart rate (Caplan \& Jones, 1975; Cobb \& Rose, 1973); psychological stress measures (Spector, 1987; Spector, Dwyer, \& Jex, 1988); and lower quality of work and job satisfaction (Kirmeyer \& Dougherty, 1988). Work overload has been named as a common source of stress for a variety of occupations such as clerical workers, soldiers, air traffic controllers, and health care workers (Bliese \& Halverson, 1996; Carayon, 1994; Iverson, Olekalns, \& Erwin, 1998; Shouksmith \& Burrough, 1988). It is also true that while having too much to do is stressful, having too little to do is stressful as well (French \& Caplan, 1972; Ganster, Fusilier, \& Mayes, 1986). A sense of lack of control is also important as a source of stress in the workplace, and particularly if the employee wants to have some input into the job and how it is done (Dwyer \& Ganster, 1991; Karasek, 1979). Interpersonal stress can be and is frequently named as a source of stress in organizations as is organizational politics and conflict (Ferris, Frink, Gilmore, \& Kacmar, 1994; Matteson \& Ivancevich, 1982). It is also true that jobs with difficult and/or uncomfortable work conditions are perceived as stressful (Frese \& Zapf, 1988).

Research in the past has found that much of the stress in organizations can be tied to such things as role conflict and role ambiguity. In addition, the role of the employee seems to effect the perception of occupational stress. If is often assumed that executives and managers (white-collar workers) perceive more role ambiguity whereas lower level employees (blue-collar) often experience more role conflict. Jackson and Schuler (1985), however, found no relationship between job level and either role conflict or role ambiguity. As the definition of job stress varies from one study to another, this confusion presents one main limitation of research on the identification of stressors in the workplace (Schuler, 1980). This dilemma may be due to the lack of a universal measurement of stressors. Two conflicting theories often applied to the study of occupational stress are Lazarus' Transactional Process Theory and the Person-Environment Theory. 
Person-Environment Theory (French, Caplan, \& Harrison, 1982) is considered one of the most widely accepted explanations for dealing with occupational stress. The theory defined occupational stress in terms of an unsuitable person-environment fit, which results in psychological strain and stress-related physical effects. Other findings, have reported that interactions between the employee and his/her work environment will predict job stress better than either the person or the environment would by himself or herself. Despite these findings, Chemers, et al. (1985), concluded that, although the Person-Environment Fit Theory was useful in measuring and defining job stress, the theory did not produce a highly focused approach. This obviously contrasts with the previously detailed account of Lazarus' Theory which defines stress in terms of the cognitive appraisal and reaction of the individual, thus providing a very specific and focused approach to defining stress (Lazarus \& Folkman, 1984).

There have been some studies of gender differences in stress-related effects, but the results are mixed and somewhat inconsistent. Most of the research concludes that there is very little evidence that gender differences induced any stress effects in the workplace. Nelson and Quick (1985), however, confirmed that women experience more occupational stress than men because of the difference in job stressors that women face (career blocks, lower salaries, discrimination, and the dynamic of domestic responsibilities and career). Other evidence suggested that workload stressors, overload or underload, were reported by women double that of men (DiSalvo, et al., 1994). Thus, gender differences may not show up in some studies because in a given work environment, men and women may respond differentially to different types of stress, and when assessment of stress allows for these differences to emerge, then they may surface. Obviously, gender differences in workplace stress are subtle, and may reflect differences in role perception between men and women.

The present study examines stress in the workplace by looking at a number of variables thought to be related to the experience of occupational stress. Occupations were selected from organizations that could be classified as either blue-collar or white-collar, and all were from about the same levels in their organizations. In addition, we examined the differential effects of different types of stressors, and finally, the gender of the employees was examined as a potentially relevant variable in the effects of workplace stress. This study was based on the Occupational Stress Model described by Matteson and Ivancevich (1980).

\section{Method}

\subsection{Subjects}

The subjects for this study were 140 employees from four different firms. Two of the firms were typical small manufacturing firms where most of the workers would be considered to be blue-collar. The seventy employees that were used as subjects included line workers, some secretaries, and some supervisors. There were 41 males and 29 females. The mean age of the subjects in these organizations was 38.7 years (males, 40.0 years; females, 30.0 years). The subjects from these organizations had worked in their respective organizations for four years with a range from one to ten years.

The other two firms were more traditionally white-collar types - one a college, and the other a health care organization. In the health care organization the subjects were line employees up to lower levels of management, but no medical or nursing personnel were used. In the college there were subjects that were departmental assistants, secretaries, lower-level administrators, and professors. There were 40 males and 30 females in this sample, and the mean age was 45.6 years (males, 47.3 years; females 42.4 years). The average employee from these latter two organizations had worked for the organization an average of eight years with a range of four to twenty years.

These organizations were used because they were representative of the different types of jobs that are generally considered to be white-collar and blue-collar. The employees that were selected as subjects were selected at different levels that were considered to be representative of the bulk of the workforce in the organizations. The gender of subjects attempted to represent the typical balance of males and females in these organizations as well. 


\subsection{Materials}

Questions for the survey were drawn from the 1995 APME Newsroom Management Committee Stress Survey, the Stress Assessment Questionnaire (Hellriegle \& Slocum, 1989), the 1996 OH\&S Hazard Sheet Stress Survey, the 1997 Job Stress Quiz, the 1986 Stress Assessment Questionnaire, and the 1998 Stress Assessment Questionnaire and Report. Questions from these sources were combined into a comprehensive Occupational Stress Survey that contained two parts. Part One of the survey contained 60 scaled questions concerning stressors in a worker's life on the job. Each question was a five-point Likert scale with responses ranging from "never, rarely, sometimes, often, and always." The questions were grouped into three categories of stressors: individual; group; and organizational. Within these three groups there were 12 variables being tested. The six variables under individual level stressors included role conflict, role ambiguity, responsibility for others, qualitative/quantitative work underload, qualitative/quantitative work overload, and harassment/sexual harassment. There were two variables under the group level stressors: cohesiveness and intragroup conflict. The four remaining variables were included in the organization-level stressors: changes in technology; physical working conditions; management styles and attitudes; and structure of the organization.

Part Two of the survey looked at the effects of occupational stress. This part of the survey contained 15 open-ended questions where the subjects could be more expressive as to how work stressors affected them. The questions involved "yes/no," multiple-choice, and ranking types of questions. After answering the specific questions, subjects then had the opportunity to expand and explain their answers. There were three major effects evaluated by these questions: behavioral; cognitive; and physiological. The behavioral effects questions asked about job satisfaction, job performance, absenteeism, turnover, accidents, and substance abuse. Decision-making, concentration, and forgetfulness were the three variables related to cognitive effects. Physical effects used questions having to do with health concerns and burnout. The final three questions asked the subjects to rank order their top five causes of stress, rank order their top three solutions to stress, and to fill in some biographical information including age, gender, name of company, years with company, and job title.

\subsection{Procedures}

The Occupational Stress Survey was administered to all subjects in all organizations. In each, there was a room set aside for taking the survey, and several different time slots were made available for subjects to take the survey that took about 30 minutes to complete. In all organizations, employees were allowed to take time off of work to complete the survey, and were not required to use their regular break times for this purpose. Following completion of the surveys they were collected and analyzed. The same experimenter presented the surveys to all subject groups, and answered questions that were asked.

\subsection{Results}

The surveys were evaluated and scored for all subjects. Because of the sample size, large number of variables, and individual differences in responding, individual questionnaire items did not yield any significant differences. Thus, the questions were collapsed into three categories of responses: individual; group; and organizational sources of stress, and the data are reported as means from the five-point scales that were used.

Table 1 contains the relevant means for the questionnaire responses from the different groups, and for the different categories of stress. 
Table 1. Mean survey scores for employee groups and types of stress.

\begin{tabular}{|l|l|c|c|c|c|}
\hline \multicolumn{2}{c|}{} & \multicolumn{4}{c|}{ Stressors } \\
\cline { 3 - 6 } \multicolumn{2}{c|}{} & Individual & Group & Organizational & Total \\
\hline \multirow{3}{*}{ Blue Collar } & Male & 1.8 & 1.9 & 2.2 & 2.0 \\
\cline { 2 - 6 } & Female & 2.1 & 2.1 & 2.3 & 2.2 \\
\cline { 2 - 6 } & Total & 1.9 & 2.0 & 2.3 & 2.2 \\
\hline \multirow{3}{*}{ White Collar } & Male & 2.2 & 2.0 & 2.2 & 2.1 \\
\cline { 2 - 6 } & Female & 2.5 & 2.8 & 2.0 & 2.4 \\
\cline { 2 - 6 } & Total & 5.3 & 1.9 & 2.4 & 2.4 \\
\hline
\end{tabular}

The mean scores in Table 1 are based on a 5-point scale with 1 being indicative of low stress, and 5 indicating higher levels of stress. One thing that is interesting is that the range of scores suggests that in the organizations surveyed, the general levels of stress are reasonably low.

A factorial ANOVA was performed to look at the effects of Type of Occupational Group (blue-collar vs. white-collar), Gender, and Type of Stress (individual, group, organizational) on responses to the stress survey. There were no significant differences based on Organizational Group or Gender, nor were there any significant interactions. However, there was a significant main effect for Type of Stress $(\mathrm{F}=5.89, \mathrm{p}<.05)$. In general, subjects experienced more organizational stress in both organizations, although the effect was more pronounced in the whitecollar group. While females tended to show higher levels of stress, the differences were not large enough to reach significance.

Data from the second half of the survey were also analyzed using a standard content analysis. The bluecollar employees reported that there had recently been turnover issues at work because of things like employees not following rules, family problems, and low pay. The major cognitive effect that they noted was impaired concentration. Some employees showed signs of burnout by feeling overwhelmed by: feelings of not being able to meet one's objectives; feelings of having too much to do and not enough time to do it; tendencies of being rude or unpleasant to co-workers; and feelings of not being justly rewarded for their efforts.

The causes of stress mentioned most frequently by the blue-collar workers were ranked as follows: supervisor conflict; poor communication with supervisor; job security; insufficient training; and changes in technology. The solutions that the blue-collar employees suggested for reducing stress on the job were: better communication with supervisor; better training; more opportunities to participate; take time for changes; and better methods of conflict resolution.

In the white-collar sample, a number of employees stated that they would leave the organization if a similar position were available in a similar organization that paid more. Although the white-collar workers did not mention many physical effects of stress, many of them mentioned the cognitive effect of forgetfulness as being stress-related. In this group of subjects the most frequently stated cause of stress was excessive workload. Other causes included (in descending rank order): organizational change/restructure; job security; too much responsibility; and lack of social support. This group ranked potential solutions to the problems of stress as follows: reduced workload; more opportunity to participate; and achievable deadlines.

\subsection{Discussion}

This study was designed to assess the types of stressors that are most significant for male and female workers in both white- and blue-collar occupations and settings. The results did not find differences in the types and amounts of stress found between the two different types of occupational groups. Nor were there any differences between male and female workers, and although there was a tendency for the females to report higher levels of stress, this was not statistically significant. However, there was a significant finding with respect to the source of stress in both types of organizations. In both, there was a clear and significant difference that indicated that the primary source of stress for workers in both types of organizations was organizational. 
It would appear from examining the data that more subjects or less variability between subjects would have led to a few more significant results. However, it also leads to another interpretation that bears further examination. One thing that this research did not identify is the extent to which there may have been very different expressions of stress relative to specific sources that may not have been picked up in the general groupings. If this is true, then other studies need to be done to tease out the extent to which varied individual stress reactions may be covered up by the apparent non-significance of more general sources. This was a particular problem with the current samples of subjects, because the level of job stress was not especially high in any given group making it impossible to tease out subtle results and interactions. These speculations can only be solved with further research.

The second part of the survey was concerned with behavioral, cognitive, and physical effects of the employees' stress. Blue-collar employees tend to exhibit slightly more behavioral effects of stress due to problems with communication and conflict with their supervisors. Interestingly, the supervisors in question do not report communication problems between management and employees, although the employees see this as a major problem. This may be for several reasons. First, the managers may be insensitive to the communication problems since most of their communication is downwards - that is, they may not be listening very well. It may also be that as they observe the communication among the employees they see no problems, and thus assume that there are no problems in other areas of the organization. It may also be that employees are not making their concerns known, and thus the managers may not be aware that the problem exists. It does seem clear that from the employees' standpoint, vertical communication is clearly a source of stress, but the management does not recognize this.

In the white-collar environment, employees were more likely to complain of cognitive effects of stress. The concerns that were raised included such things as fears for job security, excessive workload, having too much responsibility, and lack of social support in the organization. These concerns led to cognitive reactions like forgetfulness, worrying, etc. To understand the employees' concerns, one only need look at the types of organizations involved. The health care field is dynamic, unstable, and unpredictable, and fear for one's job would be understandable. In an academic environment one is always worried about budgets, cuts, layoffs, and the "publish-or perish" mentality that permeates most academic settings. Further, white-collar jobs frequently require more take-home work, and in the days of cutbacks the frequent challenge is to do more with less. Thus, the white-collar (usually salaried) employees would be expected to "pick up the slack" when staffing problems made it difficult to get things done. This too is interesting because in talking with upper management in these organizations there is little awareness or acceptance of these issues as valid sources of stress. Thus, there is little need felt to do anything about the apparent problems - to those at the top they are either not problems, or nothing can be done about them, so "live with it."

Clearly there were some findings that were interesting in the present research, but there were more questions generated than answered. For example, the present research did not allow for the determination of individual sources of stress, and was unable to target specific sources of stress for individual employees, or for particular groups of employees. Using larger samples, and also drawing from more diverse and different organizations would help as well. However, as Jackson and Schuler (1985) point out, the study of occupational stress should focus more on, "The development of good diagnostic tools for pinpointing specific aspects about one's job that are ambiguous of conflicting." In a similar vein, research should find ways to appropriately establish ways to assess both the sources and effects of stress that are more sensitive to individual and group differences. When we use the same tools to assess different people and different groups we may actually "wash out" significant differences because of the ways in which the phenomena are studied. Thus, developing methods that are specific, sensitive, and powerful, that account for general trends but pay attention to subtle differences between people and groups would be the next most logical step. 


\subsection{Future Directions}

The present research focused mainly on issues of work-related stress. However, we are also mindful of the relationship between stress and job satisfaction, and it is our intention to tie these two concepts together more closely from an assessment standpoint. It is felt that if these issues are inextricably linked in reality, then when we are assessing either of them for the purpose of improving the organization, then both need to be examined.

To the extent that stress impacts job satisfaction, and assuming that job satisfaction is related in some ways to work outcomes, then to more clearly understand these relationships should be helpful for organizations. The relationship between job satisfaction and performance is generally found to be a low (but significant) positive correlation (Iaffaldano \& Muchinsky, 1985; Petty, McGee, \& Cavender, 1984). One would expect this to be a more positive relationship, but it is assumed that performance is dependent upon many factors in addition to job satisfaction (e.g., training, experience, working conditions, quality of supervision, etc.). Suffice it to say, that "all other things being equal," job satisfaction and performance should be positively related. We no longer believe that a "happy worker is a productive worker," but neither does that mean that there is no relationship at all.

There is also found to be a relationship between absenteeism and job satisfaction, and meta-analyses show this to be a slight negative relationship (Scott \& Taylor, 1984). Once again, it would seem that there ought to be a stronger relationship between the two, but upon examination, several things become clear. First, it is difficult to ascertain when absenteeism is voluntary, and when it is out of the employee's control. Since there are many things that impact one's ability to get to work (sick children, weather, transportation, own health, etc.), it would appear that when attendance is under the control of the employee, then one would expect that the more satisfied one is with his or her job, the less likely they are to be absent from work.

Two other outcome variables show a somewhat stronger relationship with job satisfaction. For example, organizational commitment tends to correlate highly and positively with job satisfaction (Arnold \& Feldman, 1982; O'Driscoll, Ilgen, \& Hildreth, 1992; Stumpf \& Hartman, 1984). Thus, the happier one is with his or her job, the more likely they are to be committed to the organization, and vice versa. Similarly, some studies have found that lower job satisfaction is related to higher levels of turnover (Jenkins, 1993; Mobley, Griffeth, Hand, \& Meglino, 1979; Mowday, Koberg, \& McArthur, 1984. The generalization that the more one likes their job the less likely they are to leave it seems likely. Looking at it in a slightly different way, it would appear that higher levels of job satisfaction raise the threshold for someone deciding to leave their job.

It does appear that either directly or indirectly job satisfaction is related to significant organizational outcome variables. The next step, then, is to determine the relationship between job satisfaction and occupational stress. Certainly it is well documented that stress plays an important part in how well someone adapts to and enjoys their jobs and the consequences of working. We do know that people who are not effective in their jobs are generally not happy with them, and that high levels of arousal generated by stress with interfere with optimal performance in most situations (Baumeister \& Scher, 1988). It is also true that stress is related to physical illness as well. It is estimated that anywhere from 50-70\% of all forms of physical illness are related to stress (Frese, 1985). Further, when employees are on the track to burnout, they tend to develop very negative views about their jobs (Gaines \& Jermier, 1983). In general, it appears that stress exerts mainly negative effects on task performance, and it is likely that this is also related to how well one feels about their job (Motowidlo, et al., 1986).

It is assumed that if one is to deal with the negative outcomes of stress, and to try to improve job satisfaction, that it would make some sense to attack both of these problems simultaneously. A technique developed by Buff \& Nydegger (in preparation), would allow an organization to appraise both job satisfaction facets and components of work-related stress for individual employees, groups of employees, and for the organization as a whole. This technique involves ranking outcomes preferentially and then weighting them. This then allows for individual assessment of things that are problematic, satisfying, and rewarding to an individual employee. These data can also be aggregated to determine what are relevant factors related to stress or satisfaction in a given group, department, or division as well as the company as a whole. This would allow for better awareness of and management of workplace stress, but would also allow for better job satisfaction and reward systems. The data could be used for individual counseling or for Human Resource planning throughout the organization. 
Future directions of managing workplace stress must be more inclusive and integrative if they are to be successful. The present study shows that it is difficult to arrive at specific formulations of workplace stress when dealing with aggregated data that essentially erases individual differences by treating them as error. New techniques, like that proposed, are needed to address these issues more comprehensively, flexibly, and meaningfully.

\section{References}

1. Arnold H.J., \& Feldman, D.C. (1982). A multivariate analysis of the determinants of job turnover. Journal of Applied Psychology, 67, 350-360.

2. Baumeister, R.F., \& Scher, S.J. (1988). Self-defeating behavior patterns among normal individuals: Review and analysis of common self-destructive tendencies. Psychological Bulletin, 104, 3-22.

3. Caplan, R.D., \& Jones, K.W. (1975). Effects of workload, role ambiguity, and Type A personality on anxiety, depression and heart rate. Journal of Applied Psychology, 60, 713-719.

4. Carayon, P. (1994). Stressful jobs and non-stressful jobs: A cluster analysis of office jobs. Ergonomics, 37, 311 -323.

5. Chemers, M.M., Hayes, R.B., Rhodenault, F., \& Wysocki, J. (1985). A person-environment analysis of job stress: A contingency model explanation. Journal of Personality and Social Psychology, 49, 628-635.

6. Cobb, S., \& Rose, R.M. (1973). Hypertension, peptic ulcer, and diabetes in air traffic controllers. Journal of the American Medical Association, 224, 489-493.

7. Cooper, C.L., Mallinger, M., \& Kahn, R. (1978). Identifying sources of occupational stress among dentists. Journal of Occupational Psychology, 51, 227-234.

8. DiMatteo, M.R., Shugars, D.A., \& Hays, R.D. (1993). Occupational stress, life stress, and mental health among dentists. Journal of Occupational and Organizational Psychology, 66, 153-162.

9. Di Salvo, V., Lubbers, C., Rossi, A.M., \& Lewis, J. (1994). The impact of gender on work-related stress. Occupational Stress: A Handbook. New York: Taylor \& Francis.

10. Dwyer, D.J., \& Ganster, D.C. (1991). The effects of job demands and control on employee attendance and satisfaction. Journal of Organizational Behavior, 12, 595-608.

11. Ferris, G.R>, Frink, D.D., Gilmore, D.C., \& Kacmar, K.M. (1994). Understanding as an antidote for the dysfunctional consequences of organizational politics as a stressor. Journal of Applied Social Psychology, 24, 1204-1220.

12. French, J.R.P., Caplan, R.D., \& Harrison, R.V. (1982). The Mechanisms of Job Stress and Strain. Chichester, England: Wiley.

13. Frese, M. (1985). Stress at work and psychosomatic complaints: A causal interpretation. Journal of Applied Psychology, 70, 214-238.

14. Frese, M., \& Zapf, D. (1988). Methodological issues in the study of work stress: Objective vs. subjective measurement of work stress and the question of longitudinal studies. In C.L. Cooper \& R. Payne, (Eds.), Courses, Coping and Consequences of Stress at Work. (pp. 375-411). New York: Wiley.

15. Friedman, M., \& Rosenman, R.H. (1974). Type A Behavior and Your Heart. New York: Alfred A. Knopf.

16. Gaines, J., \& Jermier, J.M. (1983). Emotional exhaustion in high stress organizations. Academy of Management Journal, 31, 567-586.

17. Ganster, D.C., Fusilier, M.R., \& Mayes, B.T. (1986). Role of social support in the experience of stress at work. Journal of Applied Psychology, 71, 102-110.

18. Greenberg, J., \& Baron, R.A. (1995). Behavior in Organizations: Understanding and Managing the Human Side of Work, $5^{\text {th }} E d$. Englewood Cliffs, NJ: Prentice Hall.

19. Greenberg, J., \& Baron, R.A. (1997). Behavior in Organizations: Understanding and Managing the Human Side of Work, $6^{\text {th }} E d$. Upper Saddle River, NY: Prentice Hall.

20. Iaffaldano, M.T., \& Muchinsky, P.M. (1985). Job satisfaction and job performance: A meta-analysis. Psychological Bulletin, 97, 251-273.

21. Ivancevich, J.M. \& Matteson, M.T. (1980). Stress and Work: A Managerial Perspective. Glenville, Illinois: Scott Foresman.

22. Iverson, R.D., Olekalns, M., \& Erwin, P.J. (1998). Affectivity, organizational stressors, and absenteeism: A causal model of burnout and its consequences. Journal of Vocational Behavior, 52, 1-23.

23. Jackson, S.E. \& Schuler, RS. (1985). A meta-analysis and conceptual critique of research on role ambiguity and role conflict in work settings. Organizational Behavior \& Human Decision Process, 36, 16-78.

24. Jenkins, J.M. (1993). Self-monitoring and turnover: The impact of personality on intent to leave. Journal of Organizational Behavior, 14, 83-91.

25. Jermier, J.M., Gaines, J., \& McIntosh, N.J. (1989). Reactions to physically dangerous work: A conceptual and empirical analysis. Journal of Organizational Behavior, 10, 15-33.

26. Karasek, R. (1979). Job demands, job decision latitude, and marital strain: Implications for job redesign. Administrative Science Quarterly, 24, 285-306.

27. Kirmeyer, S.L., \& Dougherty, T.W. (1988). Work load, tension, and coping: Moderating effects of supervisor support. 
Personnel Psychology, 41, 125-139.

28. Kobasa, S.C. (1982). The hardy personality: Toward a social psychology of stress and health. In J. Suls \& G. Sanders (Eds.), The Social Psychology of Health and Illness (pp. 3-32). Hillsdale, NJ: Lawrence Erlbaum.

29. Krakowski, A.J. (1982). Stress and the practice of medicine II-stressor, stresses \& strains. Psychotherapeutics and Psychosomatics, 38, 11-23.

30. Lazarus, R.S. \& Folkman, S. (1984). Stress Appraisal and Coping. New York: Springer-Verlag.

31. Marino, K.E., \& White, S.E. (1985). Departure, structure, locus of control, and job stress: Its causes and consequences for job performance. Journal of Applied Psychology, 71, 618-629.

32. Matteson, M.T. \& Ivancevich, J.M. (1987). Controlling Work Stress. San Francisco: Jossey-Bass.

33. Mobley, W.H., Griffeth, R.W., Hand, H.H., \& Meglino, B.M. (1979). Review and conceptual analysis of the employee turnover process. Psychological Bulletin, 86, 493-522.

34. Mohler, S.R. (1983). The human element in air traffic control: Aeomedical aspects, problems, and prescriptions. Aviation, Space and Environmental Medicine, 54, 511-516.

35. Motowidlo, S.J., Packard, H.J., \& Manning, M.R. (1986). Occupational stress: Its causes and consequences for job performance. Journal of Applied Psychology, 71, 618-629.

36. Mowday, R.T. (1979). Equity theory predictions of behavior in organizations. In R.M. Steers \& L.W. Porter (Eds.), Motivation and Work Behavior ( $2^{\text {nd }}$ ed.). New York: McGraw-Hill.

37. O'Driscoll, M.P., Ilgen, D.R., \& Hildreth, K. (1992). Time devoted to job and off-job activities, interrole conflict and affective experiences. Journal of Applied Psychology, 77, 272-279.

38. Petty, M.M., McGee, G.W., \& Cavender, J.W. (1984). A meta-analysis of the relationships between individual job satisfaction and individual performance. Academy of Management Review, 9, 712-721.

39. Riggio, R.E., \& Cole, E.J. (1992). Agreement between subordinate and superior ratings of supervisory performance and effects on self- and subordinate job satisfaction. Journal of Occupational and Organizational Psychology, 65, I151-158.

40. Roeske, N.C.A. (1981). Stress and the physician. Psychiatric Annals, 11, 245-258.

41. Rosenman R.H. (1978). The interview method of assessment of the coronary-prone behavior pattern. In T.M. Dembroski, S.M. Weiss, J.L. Shields, S.G. Haynes, \& M. Feinlib (Eds.), Coronary-prone Behavior (pp. 55-69). New York: Springer-Verlag.

42. Schaubroeck, J., Ganster, D.C., \& Kemmerer, B.E. (1994). Job complexity, Type A behavior, and cardiovascular disorder: A prospective study. Academy of Management Journal, 37, 426-439.

43. Scott, K.D., \& Taylor, G.S. (1985). An examination of conflicting findings on the relationship between job satisfaction and absenteeism: A meta-analysis. Academy of Management Journal, 28, 599-612.

44. Shouksmith, G., \& Burrough, S. (1988). Job stress factors for New Zealand and Canadian air traffic controllers. Applied Psychology: An International Review, 37, 263-270.

45. Spector, P.E. (1987). Interactive effects of perceived control and job stressors on affective reactions and health outcomes for clerical workers. Work and Stress, 1, 155-162.

46. Spector, P.E., Dwyer, D.J., \& Jex, S.M. (1988). Relation of job stressors to affective, health and performance outcomes: A comparison of multiple data sources. Journal of Applied Psychology, 73, 11-19.

47. Stumpf, S.A., \& Hartman, K. (1984). Individual exploration to organizational commitment or withdrawal. Academy of Management Journal, 27, 308-329.

48. Schuler, R.S. (1980). Definition in conceptualization of stress in organizations. Organizational Behavior and Human Performance, 25, 184-215.

49. Spielberger, C.D. \& Reheiser, E.C. (19940. The Job Stress Survey: Measuring gender differences in occupational stress. Journal of Social Behavior and Personality, 9, 199-218.

50. Wolfgang, A.P. (1988). Job stress in the health professions: A study of physicians, nurses, and pharmacists. Behavioral Medicine, 14, 43-47. 
Notes 